\title{
Viability of Phakopsora pachyrhizi Urediniospores Under Simulated Southern Louisiana Winter Temperature Conditions
}

\author{
S. Park, Z.-Y. Chen, A. K. Chanda, R. W. Schneider, and C. A. Hollier, Department of Plant Pathology and Crop \\ Physiology, Louisiana State University Agricultural Center, Baton Rouge 70803
}

\begin{abstract}
Park, S., Chen, Z.-Y., Chanda, A. K., Schneider, R. W., and Hollier, C. A. 2008. Viability of Phakopsora pachyrhizi urediniospores under simulated southern Louisiana winter temperature conditions. Plant Dis. 92:1456-1462.

Soybean rust, caused by Phakopsora pachyrhizi, originally occurred in Asia. It has now spread to South America and the continental United States. This disease has the potential to cause severe economic losses to U.S. soybean growers, especially in the south, where the environmental conditions are more favorable to $P$. pachyrhizi survival during winter. In the present study, the effect of simulated southern Louisiana winter temperature conditions $\left(12^{\circ} \mathrm{C}, 14\right.$-h days and $1{ }^{\circ} \mathrm{C}$, 10 -h nights with $75 \%$ relative humidity) on soybean rust urediniospore viability was examined. It was found that urediniospore viability declined rapidly from 72 to $40 \%$ after 1 day and then decreased gradually to $17 \%$ after 7 days and $11 \%$ after 60 days. Spores stored under southern Louisiana winter conditions for 60 days still produced pustules on inoculated leaves. In comparison, the viability of spores stored at room temperature decreased gradually and reached $0 \%$ at the end of 60 days. Winter temperature treatment not only reduced spore viability but also decreased germ tube growth. In addition, soybean rust spores recovered from overwintered dry kudzu leaves were also found viable. This study indicates that soybean rust spores could survive southern Louisiana winter conditions and initiate a new cycle of infection in the next growing season.
\end{abstract}

Additional keywords: detached leaf assay, spore germination rate, spore infectivity

Phakopsora pachyrhizi, the primary causal agent of soybean rust disease, can infect soybean plants and cause quick defoliation and severe yield losses (7). This disease was first discovered in Japan in 1902 and later spread into China and other Asian countries. In recent years, the disease entered Africa and South America and has spread rapidly in these continents. $P$. pachyrhizi was first detected in South America in Paraguay in 2001, from where it was spread by wind across the border into Argentina. Between 2001 and 2003, it became established and widespread in soybean production regions of Brazil $(19,26)$. Now, soybean rust is a major emerging disease in the continental United States since its discovery in late 2004 in Louisiana (20). Soybean rust disease was reported in 9, 15, and 19 states from 2005 to 2007 , respectively, according to the United States Department of Agriculture soybean rust information website (http:// www.usda.gov/soybeanrust/). Based on model predictions, soybean rust disease is expected to become established in the

Corresponding author: Z.-Y. Chen

E-mail: zchen@agcenter.lsu.edu

Accepted for publication 2 July 2008.

doi:10.1094/PDIS-92-10-1456

(C) 2008 The American Phytopathological Society
United States but very likely restricted to the southern United States, where the fungus could overwinter in frost-free areas or areas with brief below-freezing temperatures during the winter, such as Louisiana $(9,14,17,18,25)$. Yield loss due to soybean rust was predicted as low as $10 \%$ in most of the United States and up to $50 \%$ in the Mississippi Delta and southeastern states in early, preinfestation models (25).

Temperature is one of the key factors affecting rust spore viability. Keogh (8) reported that urediniospores of $P$. pachyrhizi germinate at temperatures between 8 and $33^{\circ} \mathrm{C}$. When temperatures were kept at 4 to $5^{\circ} \mathrm{C}$ or below, urediniospores lost their viability in 5 days (15). When temperature was raised to $9^{\circ} \mathrm{C}$ or higher, $P$. pachyrhizi urediniospores could remain viable for up to 27 days (22). Kochman (10) reported significant reduced germination when dry spores were exposed to temperatures of 28.5 to $42.5^{\circ} \mathrm{C}$. The optimum temperature for rust disease development, however, is slightly different from that for viability. Levy (11) reported that natural infection by $P$. pachyrhizi in Zimbabwe is favored by a maximum temperature of 26 to $29^{\circ} \mathrm{C}$ and a minimum temperature of 15 to $17^{\circ} \mathrm{C}$. Under controlled environmental conditions, no infection was observed at temperatures of $27.5^{\circ} \mathrm{C}$ or higher $(12,13)$. Rust disease development also was greatly inhibited when mean night temperature dropped below $14^{\circ} \mathrm{C}$ and was stopped when night temperature reached below $9^{\circ} \mathrm{C}(13,23)$. In addition to temperature, humidity also affects soybean rust disease development in the field. Melching et al. (13) indicated that humidity of over $80 \%$ for 4 to $6 \mathrm{~h}$ was necessary for disease development and urediniospores lost their infectivity completely after 8 days on dry foliage.

However, the main concern for soybean growers in the United States is whether $P$. pachyrhizi urediniospores can survive winter conditions in the southern United States, such as Louisiana, and cause a new cycle of infection in the next growing season. Therefore, the objective of this study was to examine the viability and infectivity of soybean rust spores exposed to simulated winter conditions $\left(12^{\circ} \mathrm{C}, 14\right.$-h days and $1{ }^{\circ} \mathrm{C}, 10$-h nights with $75 \%$ relative humidity) for various durations. Additionally, overwintered kudzu leaves were collected on 30 January 2008 from the field where soybean rust had been reported for in the past 2 years to determine whether overwintered soybean rust spores were still viable.

\section{MATERIALS AND METHODS}

Materials. Soybean rust (P. pachyrhizi) urediniospores were collected from infected soybean leaves in October 2006 at Central Research Station, Louisiana State University, Baton Rouge. Spores were collected from infected soybean leaves (R8 stage) in the field using a handheld vacuum in the early afternoon. Spores were stored at $-80^{\circ} \mathrm{C}$ before they were used for experiments, and they were termed frozen spores, which means 0 day or nonwinter treatment in the present study. Soybean plants (cv. 93M60, Pioneer) were grown in 20-cm-diameter plastic pots (four plants per pot) in the greenhouse. The third to fifth trifoliolate leaves at R1 to R2 stages were used in the detached leaf assays.

Winter treatment of urediniospores. Subsamples of urediniospores $(1 \mathrm{mg})$ from $-80^{\circ} \mathrm{C}$ were stored in $1.5-\mathrm{ml}$ microcentrifuge tubes (with lid open). The tubes were maintained either at room temperature $\left(25^{\circ} \mathrm{C}\right)$ inside a sealed box with a relative humidity maintained at $75 \%$ using a saturated $\mathrm{NaCl}$ solution or under simulated southern Louisiana winter conditions $(12 \pm$ $1{ }^{\circ} \mathrm{C}, 14$-h day with a light intensity of 50 $\mu \mathrm{E} \mathrm{s} \mathrm{s}^{-1} \mathrm{~m}^{-2}$ and $1 \pm 1^{\circ} \mathrm{C}, 10$-h night with $75 \%$ relative humidity) for up to 60 days in a diurnal incubator. Winter-treated spore samples were removed daily during the 
first 7 days to examine the effect of shortterm winter treatment on spore viability. For the long-term effect of winter treatment on spore viability, germ tube development, and infectivity, winter-treated spore samples were removed at $0,4,14$, 30,44 , and 60 days from the experimental conditions and examined. The simulated southern Louisiana winter conditions were based on the high and low average winter temperatures recorded from southern Louisiana (Cameron, Vermilion, St. Mary, and Lafourche Parishes) to Louisiana (Vernon, Rapides, and Avoyelles Parishes) in the past 30 years during December and January (http://www.weather.com) (Table 1). The studies were conducted three times, with three replicates for each time point. Means were separated by a least significant difference (LSD) test at $P=0.05$ using the Statistical Analysis System (version 9.1; SAS Institute, Cary, NC).

Viability of urediniospores and germ tube growth. Soybean rust urediniospores in microcentrifuge tubes ( $1 \mathrm{mg} /$ tube $)$ were removed from simulated winter temperature conditions after $0,4,14,30,44$, and 60 days. Spores were resuspended in $1 \mathrm{ml}$ of deionized water containing $0.01 \%$ Tween 20 and allowed to germinate at room temperature for $12 \mathrm{~h}$ (3) along with control spores that had been kept at room temperature for the same period of time. Spore viability under different conditions was assessed using spore germination rate, which was defined as the percentage of spores germinated. At the end of incubation, the spore suspension was mixed and three 20- $\mu$ l subsamples were removed from the microcentrifuge tube and examined with a microscope. The percentage of spores germinated was determined based on the total number of germinated spores versus total number of spores counted from at least 25 different fields of view (at $\times 200$ magnification) for each sample. The highest number of spores seen in a field was 44 and the lowest number was 15 , with an average of $26.8 \pm 6.1$ spores per field. The germination percentage for each time point was the mean from three replicated samples.

For determining germ tube growth, three 20- $\mu$ l subsamples of winter-treated and frozen spore suspensions were removed from the water suspension in microcentrifuge tubes at various times ranging from 0 to $10 \mathrm{~h}$ and examined microscopically. Images of germinated spores from at least 25 different fields of view for each sample were captured by a Spot RT camera (Diagnostic Inc., Sterling Heights, MI) attached to the microscope. The germ tube length of each germinated spore was measured using the Spot Advance software (Diagnostic Inc.). The mean germ tube length for each time point was determined from two repeated experiments, each with three replicated samples. Means were separated by the LSD test at $P=0.05$.
Inoculation of detached soybean leaves with $P$. pachyrhizi. The infectivity of rust spores which had been stored under simulated Louisiana winter conditions for various durations $(0,4,14,30,44$, and 60 days) was assessed using an in vitro detached leaf assay. Winter-treated and frozen spores were resuspended in deionized water containing $0.01 \%$ Tween 20 . Spore concentration was determined using a hemacytometer and adjusted to 2,500 spores/ml. Inoculum $(200 \mu \mathrm{l})$ containing 500 spores was applied evenly to the adaxial surfaces of detached soybean leaves that had been washed three times with deionized water and air dried. Inoculated leaves were placed adaxial surface up on filter paper soaked with sterile water in petri dishes. The inoculated leaves were incubated under the following conditions: $26 \pm 0.5^{\circ} \mathrm{C}, 16$-h day (about $50 \mu \mathrm{E} \mathrm{s}^{-1} \mathrm{~m}^{-2}$ ) and $20 \pm 0.5^{\circ} \mathrm{C}, 8$-h night. Pustule forma-

Table 1. Average high and low temperatures during December and January in southern and northern Louisiana in the past 30 years $^{\mathrm{x}}$

\begin{tabular}{|c|c|c|c|c|}
\hline \multirow[b]{3}{*}{ Month } & \multicolumn{4}{|c|}{ Mean temperature $\left({ }^{\circ} \mathrm{C}\right) \pm$ standard deviation } \\
\hline & \multicolumn{2}{|c|}{ Southern Louisiana ${ }^{y}$} & \multicolumn{2}{|c|}{ Northern Louisiana $^{\mathrm{z}}$} \\
\hline & High & Low & High & Low \\
\hline December & $17.1 \pm 0.7$ & $5.5 \pm 1.1$ & $14.5 \pm 0.8$ & $3.0 \pm 0.8$ \\
\hline January & $16.6 \pm 2.6$ & $4.4 \pm 1$ & $13.0 \pm 0.9$ & $1.8 \pm 0.9$ \\
\hline
\end{tabular}

${ }^{x}$ Data were compiled from http://www.weather.com.

${ }^{y}$ Mean high and low temperatures of 19 parishes in southern Louisiana between December and January: Vernon, Rapides, Avoyelles, Beauregard, Allen, Evangeline, St. Landry, Pointe, Coupee, East Baton Rouge, Tangipahoa, Washington, Calcasieu, Acadia, Iberville, Cameron, Vermilion, Iberia, and St. Charles.

${ }^{\mathrm{z}}$ Mean high and low temperatures of 10 parishes in northern Louisiana between December and January: Union, Morehouse, East Carroll, Bienville, Jackson, Madison, Nachitoches, Winn, Tensas, and Grant.

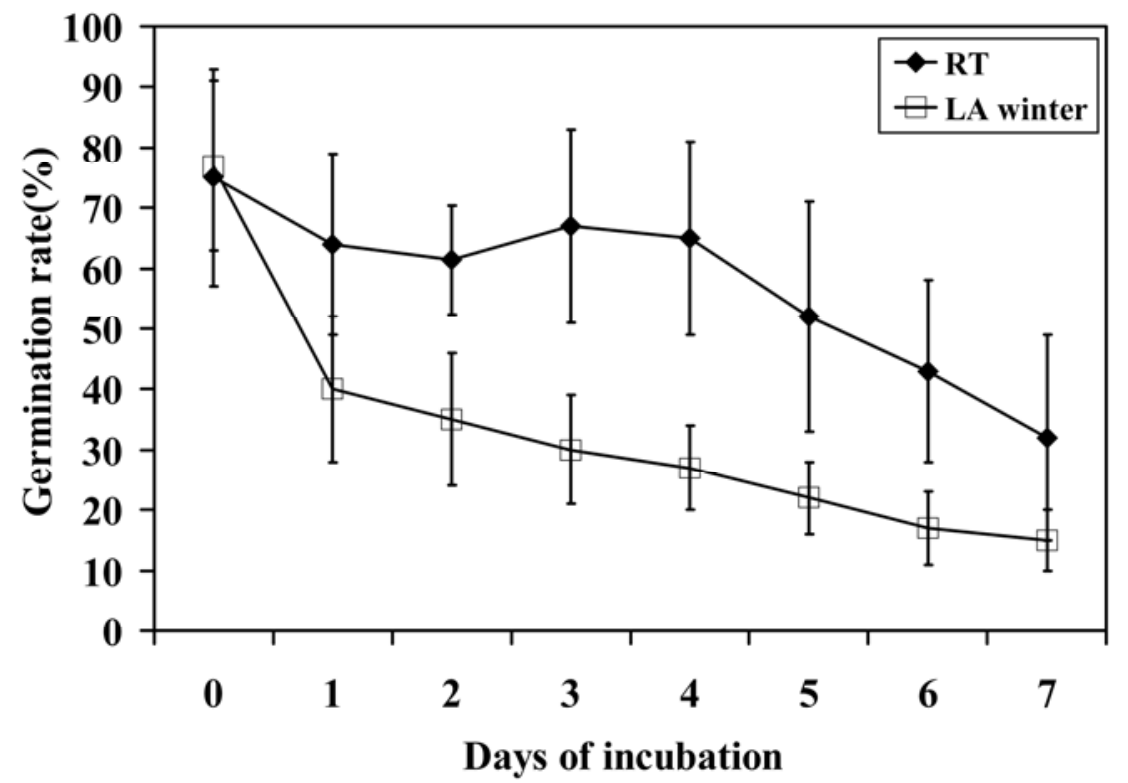

Fig. 1. Effect of short-term winter temperature treatment on the germination rate of Phakopsora pachyrhizi urediniospores. Germination rate of winter-treated spores (up to 7 days) was compared daily with control spores kept at room temperature for the same duration. Germination rate was measured as the percentage of spores germinated at room temperature after being suspended in deionized water containing $0.01 \%$ Tween 20 for $12 \mathrm{~h}$. RT, room temperature $\left(25-26^{\circ} \mathrm{C}\right)$; LA winter, simulated southern Louisiana winter conditions $\left(12^{\circ} \mathrm{C}, 14\right.$-h day and $1^{\circ} \mathrm{C}, 10$-h night with $75 \%$ relative humidity). Vertical bars represent standard deviation. 


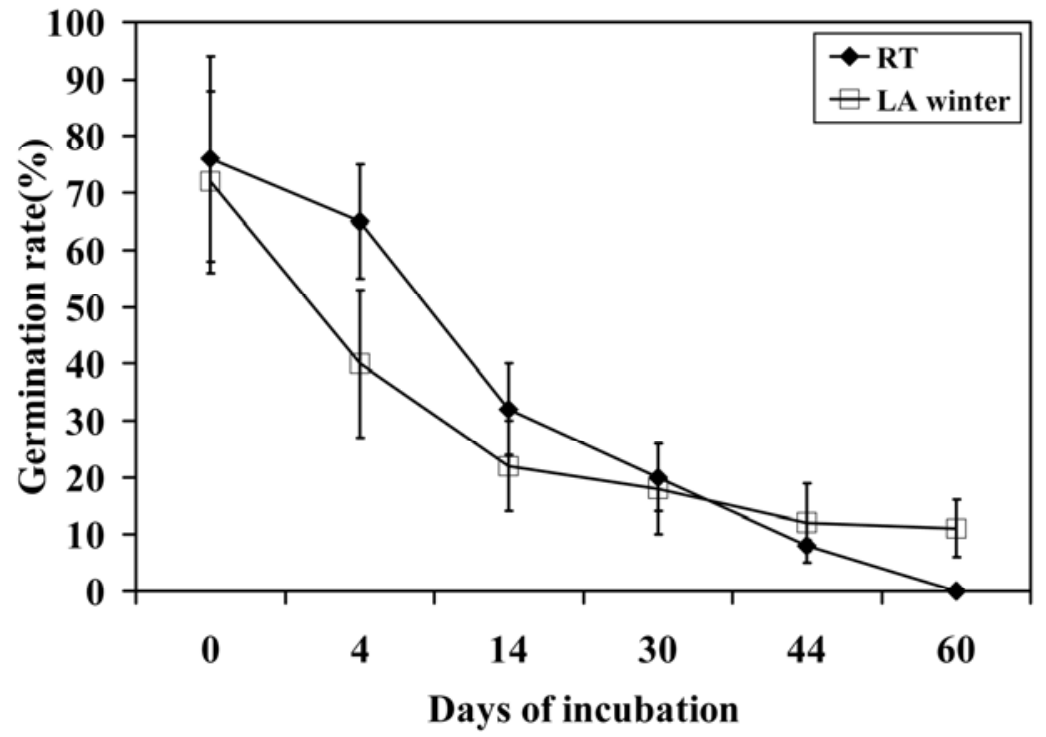

Fig. 2. Effect of long-term winter temperature treatment on the germination of Phakopsora pachyrhizi urediniospores. Germination rate of winter-treated spores (up to 60 days) was compared with control spores kept at room temperature for the same duration. Germination rate was measured as the percentage of spores germinated at room temperature after being suspended in deionized water containing $0.01 \%$ Tween 20 for $12 \mathrm{~h}$. RT, room temperature $\left(25-26^{\circ} \mathrm{C}\right)$; LA winter, simulated southern Louisiana winter conditions $\left(12^{\circ} \mathrm{C}, 14-\mathrm{h}\right.$ day and $1{ }^{\circ} \mathrm{C}, 10$-h night with $75 \%$ relative humidity). Vertical bars represent standard deviation.

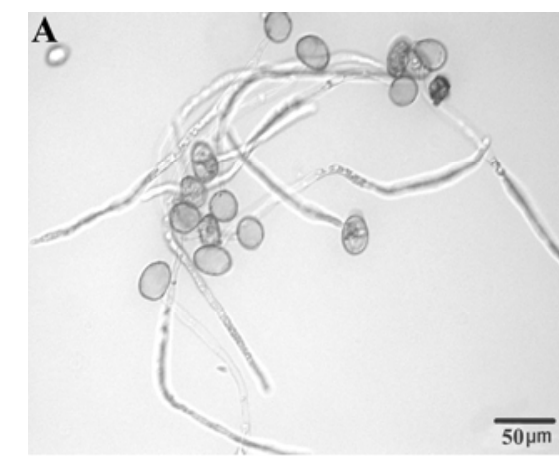

$\mathbf{B}$

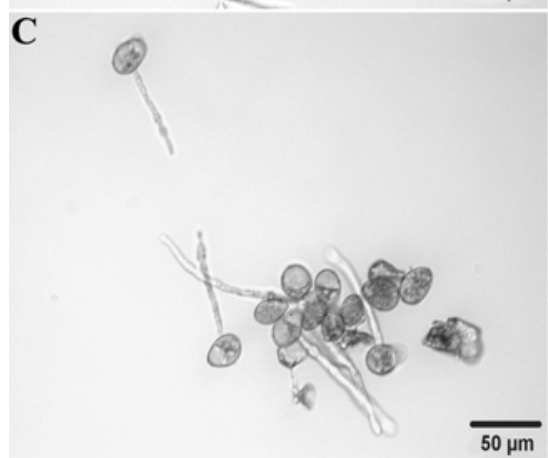

$\mathbf{E}$

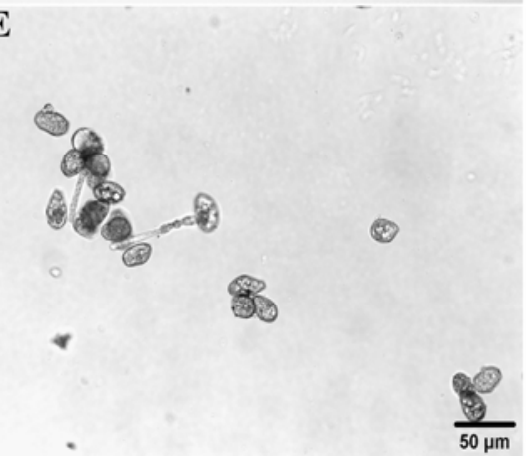

F

D
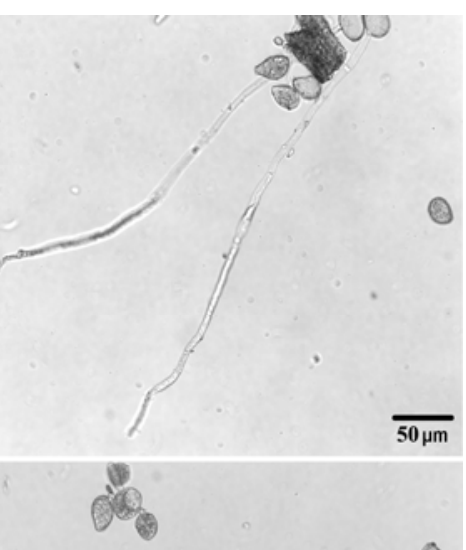

,

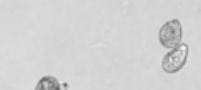

6)
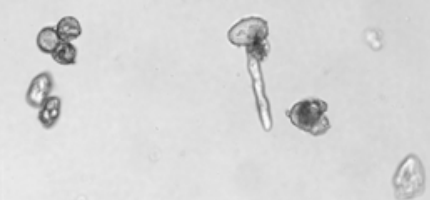

$\overline{50 \mu \mathrm{m}}$

Fig. 3. Effect of simulated winter temperature treatment on Phakopsora pachyrhizi urediniospore germ tube development. Germ tube growth was examined after incubating frozen spores and overwintered rust spores in deionized water containing $0.01 \%$ Tween 20 at room temperature for $10 \mathrm{~h}$. A, Frozen spores; BF, spores that had been under simulated winter conditions for 4, 14, 30, 44, and 60 days, respectively. the two locations in southern Louisiana (New Iberia) where soybean rust on kudzu had been reported in the past two consecutive years. These earlier-infected kudzu leaves had senescenced at the end of the growing season and fallen off vines during the winter. The collected leaves were first examined with a dissecting microscope (Leica MZ16) to confirm pustule lesions at $\times 200$. Leaves with lesions were then sliced into 3-by-5-mm sections and transferred to a 15-ml centrifuge tube with sufficient deionized water containing $0.01 \%$ Tween 20 to submerge all leaf sections. After $12 \mathrm{~h}$ of incubation at room temperature, the spore suspensions were examined with a microscope for viability.

\section{RESULTS}

Effect of simulated southern Louisiana winter temperature conditions on $P$. pachyrhizi urediniospore viability. The average germination rate of urediniospores freshly harvested from the field varied greatly (from 93 to $15 \%$ ) depending on the time of harvest and the microenvironment which the spores were exposed to before harvest (S. Park and Z.-Y. Chen, unpublished data). Spores can be stored at $-80^{\circ} \mathrm{C}$ for up to 1 year without showing a further decline in germination rate $(5,21)$. The spores used for this study had an average germination rate of 72 to $80 \%$. Frozen soybean rust urediniospores stored at room temperature $\left(25^{\circ} \mathrm{C}\right)$ lost their viability gradually from 72 to $32 \%$ in 7 days, whereas the viability of spores stored under simulated winter conditions decreased from 72 to $40 \%$ in the first $24 \mathrm{~h}$, followed by a steady decrease to about $17 \%$ at the end of 7 days (Fig. 1). Spores kept at room temperature had a significantly higher viability than that of winter-treated spores after 2 days of storage (Fig. 1). However, the difference in viability between spores kept at room temperature and under winter conditions diminished as the time increased and became insignificant at day 7 (Fig. 1).

In an effort to determine how long soybean rust spores remain viable under simulated southern Louisiana winter temperature conditions, the germination rate of spores was examined biweekly for up to 60 days in a separate experiment. It was found that spore germination rate decreased rapidly from 72 to about $22 \%$ in 14 days, and then more slowly to $11 \%$ at 60 days when stored under simulated winter temperature conditions (Fig. 2). However, the germination rate of control spores kept at room temperature decreased from 76 to $32 \%$ in the first 2 weeks (Fig. 2), and then decreased steadily to 20 and $8 \%$ at 30 and 44 days, respectively. Spore germination rate reached $0 \%$ at the end of this 60-day study (Fig. 2).

Effect of simulated winter-temperature treatment on spore germ tube growth. Simulated winter-temperature 
treatment not only reduced spore viability but also slowed spore germ tube growth (Fig. 3). Germ tube development for frozen spores was clearly visible after $2 \mathrm{~h}$ of germination and elongated rapidly between 4 and $8 \mathrm{~h}$. Germ tube length reached an average of $90 \mu \mathrm{m}$ after $4 \mathrm{~h}$ and an average of $250 \mu \mathrm{m}$ at the end of $10 \mathrm{~h}$ of incubation (Fig. 4). Germ tube length of wintertreated spores was significantly shorter than frozen spores after $2 \mathrm{~h}$ of germination, except for the spores that were winter treated for only 4 days (Fig. 4) The average germ tube length was $30 \mu \mathrm{m}$ at the end of $10 \mathrm{~h}$ of germination for the spores that had been treated for 14 days or longer, which was about eight times shorter than those of frozen spores (Fig. 4). The average germ tube growth rate for frozen spores and spores under winter conditions for 4 days was about $25 \mu \mathrm{m} / \mathrm{h}$ compared with that of $3 \mu \mathrm{m} / \mathrm{h}$ for the spores that had been under winter temperature conditions for 14 to 60 days.

Effect of winter treatment on spore infectivity using a detached leaf assay. Detached soybean leaves started producing roots about 7 days after incubation under the detached-leaf assay conditions, enabling leaves to remain green up to 30 days after inoculation (Fig. 5). Spores that had been treated under simulated winter temperature conditions for as long as 60 days retained their infectivity and were able to produce new pustules when inoculated onto detached soybean leaves (Fig. 6), although the number was significantly less compared with that produced by frozen spores (Table 2). Pustules were observed 9 days after inoculation on all soybean leaves inoculated with frozen or 4-day-old overwintered spores (Table 2). For leaves inoculated with 14- or 30-day-old overwintered spores, the initial pustules were observed 9 days after inoculation but only in 85 or $25 \%$ of the inoculated leaves, respectively. Infectivity decreased as the duration of winter treatment increased. Leaves inoculated with spores that had overwintered for 44 and 60 days did not develop pustules until 12 days after inoculation, and pustules were observed in only 40 and $10 \%$ of the inoculated leaves, respectively (Table 2).

In addition, pustule density in inoculated leaves decreased as the duration of winter treatment increased. Fourteen days after inoculation, leaves inoculated with frozen or 4-day-old overwintered spores had an average of 42.3 or 49.2 pustules/leaf, respectively (Table 2). However, the pustule density was significantly lower in leaves inoculated with spores overwintered for 14 days or longer compared with leaves inoculated with frozen spores. On average, only 16 and 3 pustules per inoculated leaf were observed in leaves inoculated with spores that overwintered for 14 and 30 days, respectively. Leaves inoculated with spores overwintered for 44 or 60 days had an average of less than one pustule per inoculated leaf (Table 2).

Viability of soybean rust spores on overwintered kudzu leaves. No viable soybean rust spores were recovered from kudzu leaves collected from one location. However, 67 of about 500 spores recovered from an overwintered dry kudzu leaf at the other location were found to germinate after $12 \mathrm{~h}$ of incubation in water containing $0.01 \%$ Tween 20 (Fig. 7). In addition, germ tube growth of these viable spores reached an average of $25 \pm 4.7$ after $10 \mathrm{~h}$ of germination, which was about the same as those of spores that had been treated under simulated winter for 60 days.

\section{DISCUSSION}

Soybean rust urediniospore survivability under winter conditions, especially in the south, is a major concern for U.S. soybean growers. Previous studies determined the maximum and minimum temperature and moisture conditions for spore germination

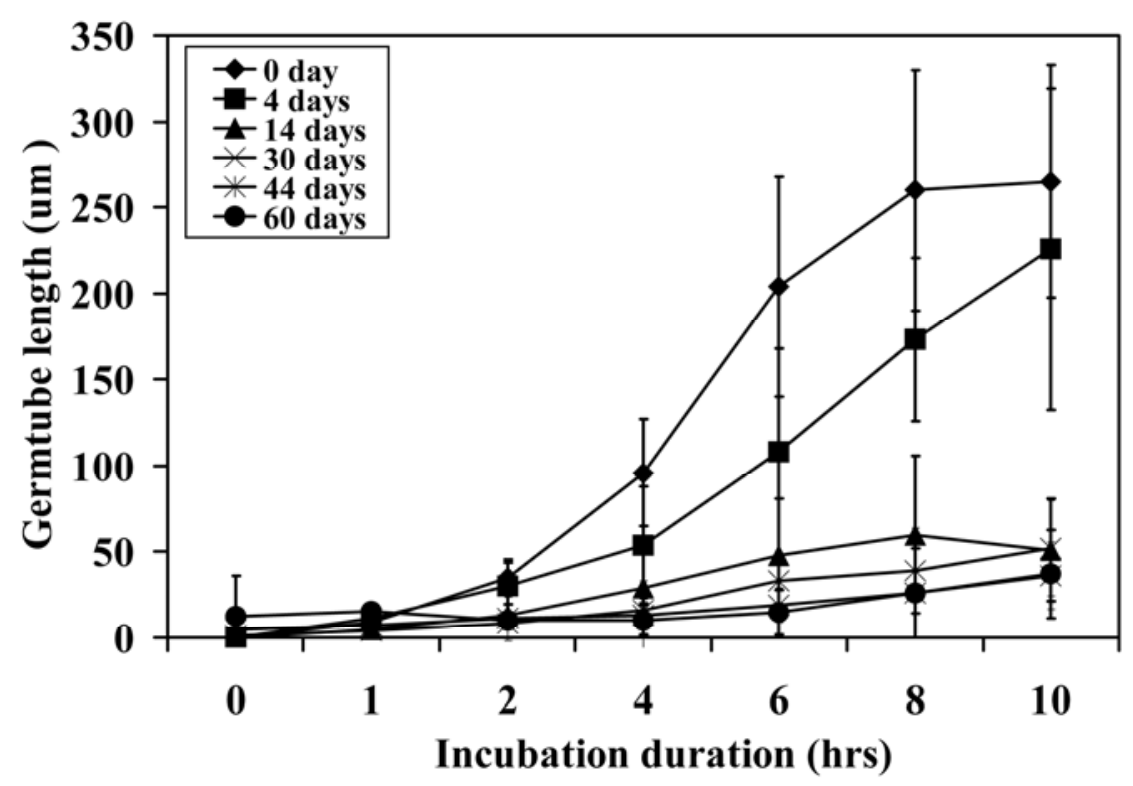

Fig. 4. Effect of winter treatment on germ tube growth rate of Phakopsora pachyrhizi urediniospores. Germ tube length was measured with a light microscope hourly after suspending the frozen and winter-treated spores in deionized water containing $0.01 \%$ Tween 20 at room temperature. The data presented here were means from two repeated experiments, each with three replicates. Vertical bars represent standard deviation.
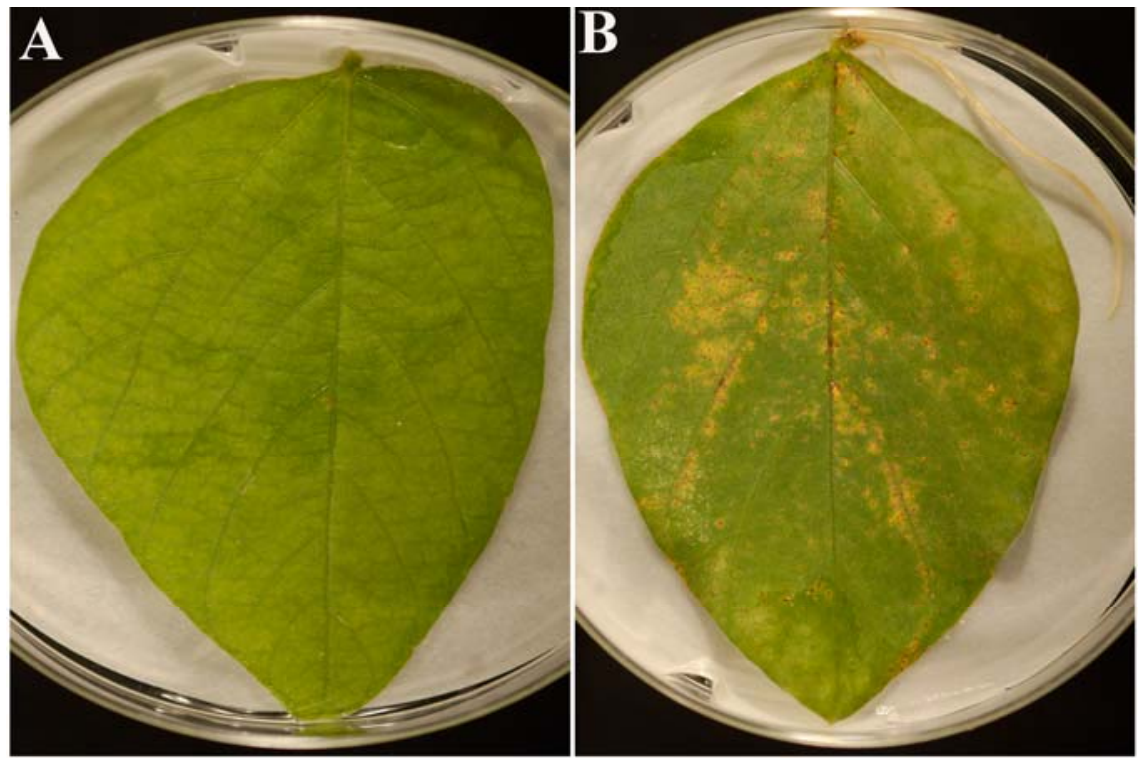

Fig. 5. Evaluation of Phakopsora pachyrhizi urediniospore infectivity using a detached-leaf assay. Soybean leaves (third to fifth trifoliate) at R1 to R2 stage were harvested from greenhouse-grown 93M60 soybean plants, inoculated with soybean rust spores, placed on filter paper soaked with deionized water, and incubated for 14 days under the condition of $26^{\circ} \mathrm{C}, 16$-h day and $20^{\circ} \mathrm{C}, 8$-h night before being evaluated for disease severity or pustule density. A, Leaf before inoculation and $\mathbf{B}$, leaf 14 days after inoculation. Root formation was evident in the detached leaves after 1 week of incubation. 


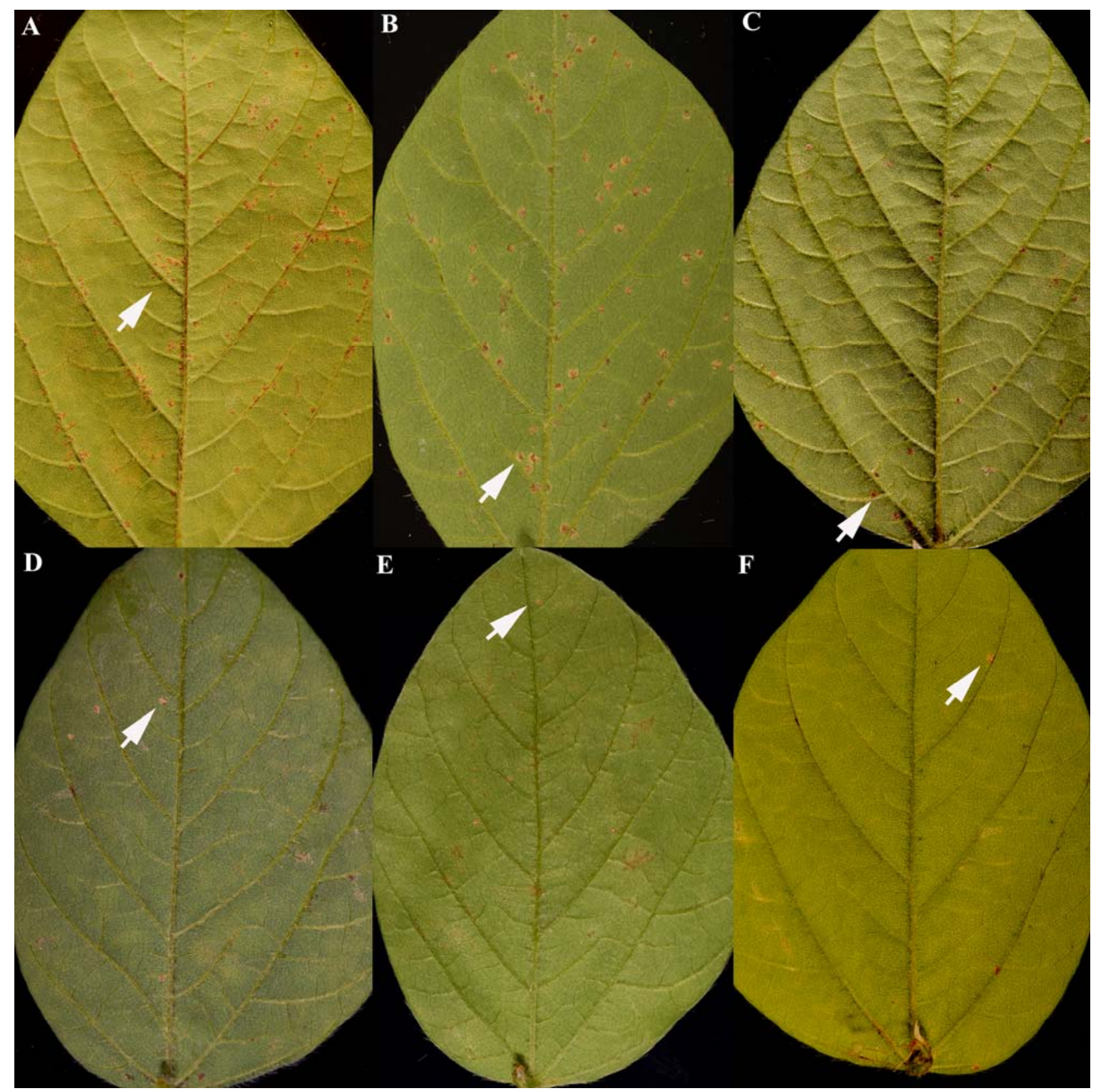

Fig. 6. Effect of winter temperature treatment on infectivity of soybean rust urediniospores. Detached soybean leaves were inoculated with rust spores that had been treated under simulated southern Louisiana winter condition for different durations. Soybean leaves were inoculated with spores overwintered for $\mathbf{A}, 0$ day (frozen spores); B, 4 days; $\mathbf{C}, 14$ days; D, 30 days; E, 44 days; and F, 60 days. Photos were taken 14 days after inoculation. Arrows indicate pustules.

and infection $(10,12,13)$. It was also reported that, when temperatures were kept at 4 to $5^{\circ} \mathrm{C}$ or lower, urediniospores lost their viability in 5 days (15). However, it has not been investigated how well soybean rust spores overwinter in the southern United States, where winter night temperature is usually above $0^{\circ} \mathrm{C}$. As a first step, a simulated winter condition based on average day and night temperatures from central to southern Louisiana during the past 30 years was used to treat frozen spores for various durations before examining their viability and infectivity.

In agreement with earlier studies $(12,15)$, soybean rust spore viability was found to be detrimentally affected by lowtemperature treatment. The effect of simu- lated winter temperature conditions on spore viability was observed within the first $24 \mathrm{~h}$ and viability was significantly decreased after 2 days compared with spores kept under room-temperature conditions. This sudden initial decline in spore viability might be related to age variations among the collected spores because it had been previously reported that viability of spores from inactive pustules was significantly lower than that of spores from active pustules when exposed to freezing temperatures (16). It also appeared that spores kept under simulated winter conditions remained viable longer than spores stored at room temperature. It has been reported that cellular metabolism is reduced at suboptimal temperatures (6). This may explain why spores with limited nutrient and energy reserves survived longer under simulated winter conditions than under room temperature.

Our study also found that simulated winter treatment slowed germ tube growth. The average germ tube growth for spores that had been under winter conditions for 14 to 60 days was about eightfold slower than that of frozen spores. This may be why those spores were less effective than frozen spores in producing pustules when inoculated onto detached soybean leaves. The time of initial symptom appearance, infection rate, and pustule density were delayed or reduced in leaves inoculated with spores that had been treated under simulated winter conditions for 44 days or 
Table 2. Effect of simulated winter temperature treatment on Phakopsora pachyrhizi urediniospore infectivity

\begin{tabular}{|c|c|c|c|c|}
\hline \multirow[b]{2}{*}{ Duration at winter conditions } & \multicolumn{3}{|c|}{ Infection rate $(\%)^{y}$} & \multirow[b]{2}{*}{ Pustule density $(\text { mean } \pm \text { SD })^{z}$} \\
\hline & 9 DAI & 12 DAI & 14 DAI & \\
\hline$\overline{0 \text { day }}$ & 100 & 100 & 100 & $42.3 \pm 28.7 \mathrm{a}$ \\
\hline 4 days & 100 & 100 & 100 & $49.2 \pm 31.8 \mathrm{a}$ \\
\hline 14 days & 85 & 100 & 100 & $16.4 \pm 9.3 b c$ \\
\hline 30 days & 25 & 70 & 85 & $3.3 \pm 4.6 \mathrm{c}$ \\
\hline 44 days & 0 & 40 & 50 & $1.5 \pm 2.4 \mathrm{c}$ \\
\hline 60 days & 0 & 10 & 30 & $0.4 \pm 0.8 \mathrm{c}$ \\
\hline
\end{tabular}

y Infection rate was the average percentage of inoculated leaves developing visible pustules at the specified time intervals; DAI = days after inoculation.

${ }^{z}$ Pustule density was the mean number of pustules per leaf observed 15 days after inoculation from two combined experiments. Means in the same column followed by a common letter were not significantly different by least significant difference test at $P=0.05 ; \mathrm{SD}=$ standard deviation.

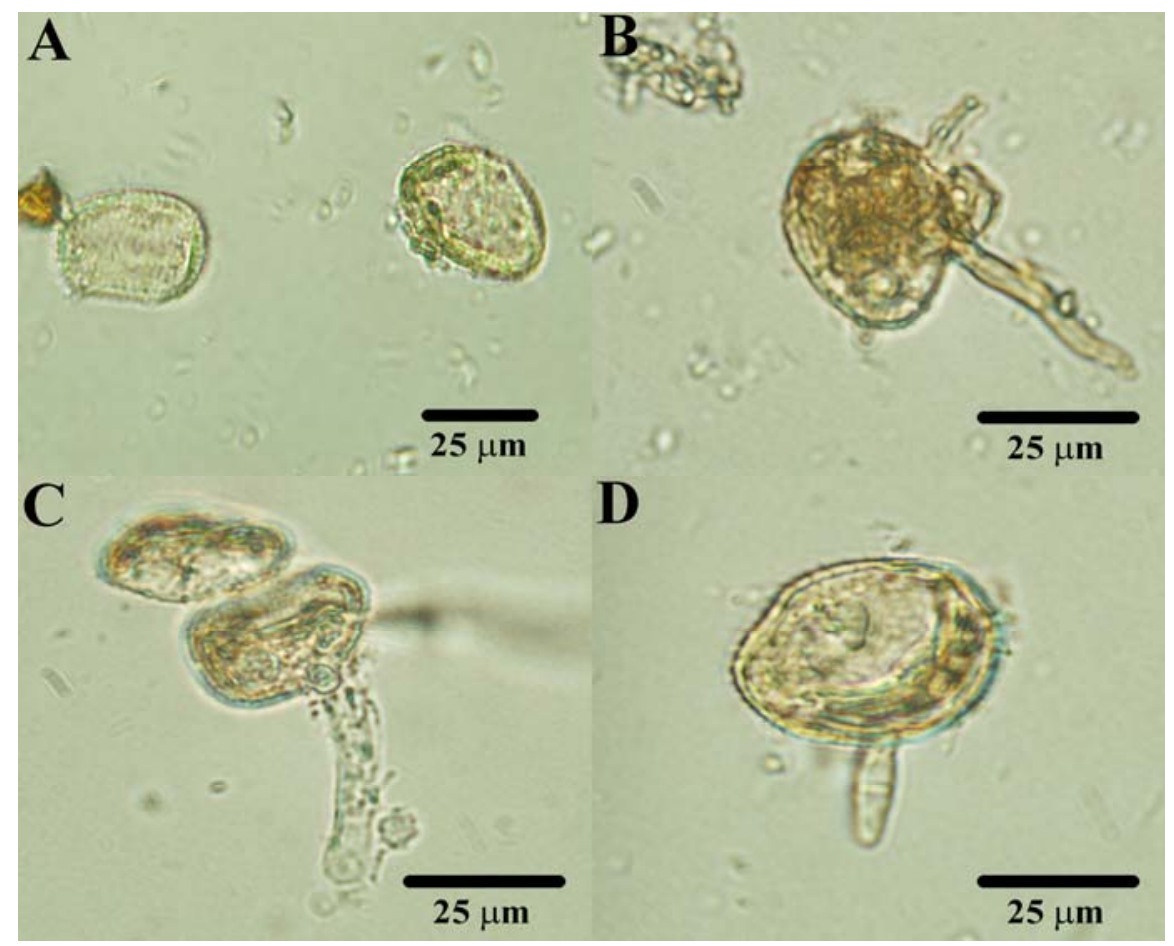

Fig. 7. Germination of Phakopsora pachyrhizi spores recovered from overwintered dry kudzu leaves collected from southern Louisiana. Spore germination was examined with a light microscope. A, spores before incubation; B-D, spores after $12 \mathrm{~h}$ incubation.

longer. However, it was demonstrated that even spores overwintered for 60 days were able to infect soybean leaves and produce pustules. It indicated that $P$. pachyrhizi urediniospores could overwinter in southern Louisiana and initiate a new cycle of infection in the next growing season, although the initial infection cycle may take longer than 14 days.

The spores overwintered for 4 days had a germ tube growth rate similar to frozen spores but a germination percentage $(35 \%)$ significantly lower than frozen spores (72\%). In the detached leaf assay, both kinds of spores showed the same infectivity. This suggests that germ tube growth rate is a more important factor than spore viability in determining whether a successful infection can occur. This may be due to the fact that $P$. pachyrhizi spores have only 6 to $8 \mathrm{~h}$ to germinate, elongate a germ tube, and penetrate the host cell wall (13) before spores exhaust their limited nutrients and energy reserves (4). A study by Adendorff and Rijkenberg (1) reported that germ tubes of direct penetrating fungi, like soybean rust, prefer the junction area between two leaf epidermal cells, and penetration usually occurs $6 \mathrm{~h}$ after inoculation. Therefore, it is likely that spores with fastelongating germ tubes will have a better chance of finding an appropriate surface area for penetration than spores with slowgrowing germ tubes before the window of opportunity elapses.

A new detached-leaf assay was used in the present study to examine changes in spore infectivity after the winter treatment. The earlier detached-leaf assay developed by Burdon and Marshall (2) and modified by Twizeyimana et al. (24) uses $1 \%$ agar plates supplemented with kinetin at 10 $\mathrm{mg} / \mathrm{liter}$ to delay leaf senescence. Also, the earlier assay uses only a small section of a leaf per petri dish. Our method, first reported by Chen et al. (3), uses whole leaves placed on sterile filter papers presoaked with $4 \mathrm{ml}$ of sterile water per 100$\mathrm{mm}$ petri dish without agar medium or kinetin. Another difference is that the de- tached leaves in this new assay were incubated under light and temperature settings of 14-h days (at $26^{\circ} \mathrm{C}$ ) and 10-h nights (at $20^{\circ} \mathrm{C}$ ). Detached leaves remained green for over a month. In addition, detached leaves in this new assay often developed roots during the first 10 days of incubation, which further delayed leaf senescence. This assay proved very useful not only in determining spore infectivity in a short time but also in maintaining live soybean rust cultures under laboratory conditions. This assay could also be used to evaluate host resistance levels of different soybean cultivars under laboratory conditions.

In summary, soybean rust spores that had been stored under simulated Louisiana winter temperature conditions for as long as 60 days germinated, infected detached soybean leaves, and produced pustules though at a lower rate and density compared with frozen spores. This study suggests that $P$. pachyrhizi could survive winter temperatures in southern Louisiana and other southern states and serve as a source of inoculum for the coming season in North America. This conclusion is supported by the observation of viable soybean rust spores recovered from overwintered dry kudzu leaves collected on 30 January 2008 from southern Louisiana, where night temperatures dipped below freezing $\left(-1^{\circ} \mathrm{C}\right)$ four times in January alone. It is also supported by the fact that the first two 2007 soybean rust infections in Louisiana were reported on newly grown kudzu leaves at the two locations where soybean rust was reported in 2006 even though all of the earlier infected kudzu leaves and vines had died back during the 2005-06 winter (www.sbrusa.net).

\section{ACKNOWLEDGMENTS}

This study was supported by Louisiana State Soybean and Small Grain Promotion Board. We thank C. A. Clark and J. W. Hoy for critical reviewing of the manuscript and N. Hazard for technical assistance. Published with the approval of the Director of the Louisiana Agricultural Experiment Station as manuscript number 2008-240-1404.

\section{LITERATURE CITED}

1. Adendorff, R., and Rijkenberg, F. H. J. 2000. Scanning electron microscopy of direct host leaf penetration by urediospore-derived infection structures of Phakopsora apoda. Mycol. Res. 104:317-324.

2. Burdon, J. J., and Marshall, D. R. 1981. Evaluation of Australian native species of Gly- 
cine for resistance to soybean rust. Plant Dis. 65:44-45.

3. Chen Z.-Y., Park, S., Hazard, N., Mumma, P., and Schneider, R. W. 2006. Proteome analysis of greenhouse-grown soybean plants inoculated with Phakopsora pachyrhizi. Proceeding of the National Soybean Rust Symposium, St. Louis. Plant Management Network. Online publication.

4. Davis, R. M., Hao, J. J., Romberg, M. K., Nunez, J. J., and Smith, R. F., 2007. Efficacy of germination stimulants of sclerotia of Sclerotium cepivorum for management of white rot of garlic. Plant Dis. 91:204-208

5. Furtado, G. Q., Alves, S. A. M., Czermainski, A. B. C., and Massola, N. S. 2008. Preservation of Phakopsora pachyrhizi uredospores. J. Phytopathol. 156:62-64.

6. Gottlieb, D., and Caltrider, P. G., 1963. Synthesis of enzymes during germination of fungus spores. Nature 197:916-917.

7. Hartman, G. L., Wang, T. C., and Tschanz, A. T. 2001. Soybean rust development and the quantitative relationship between rust severity and soybean yield. Plant Dis. 75:596-600.

8. Keogh, R. C. 1974. Studies on Phakopsora pachyrhizi Syd., the casual agent of soybean rust: M.Sc. thesis, University of Sydney, Australia.

9. Kim, K. S., Wang, T. C., and Yang, X. B. 2005. Simulation of apparent infection rate to predict severity of soybean rust using a fuzzy logic system. Phytopathology 95:1122-1131.

10. Kochman, J. K. 1979. The effect of temperature on development of soybean rust (Phakopsora pachyrhizi). Aust. J. Agric. Res. 30:273277.
11. Levy, C. 2005. Epidemiology and chemical control of soybean rust in southern Africa. Plant Dis. 89:669-674.

12. Marchetti, M. A., Melching, J. S., and Bromfield, K. R. 1976. The effects of temperature and dew period on germination and infection by urediospores of Phakopsora pachyrhizi. Phytopathology 66:461-463.

13. Melching, J. S., Dowler, W. M., Koogle, D. L., and Royer, M. H. 1989. Effect of duration, frequency, and temperature of leaf wetness periods on soybean rust. Plant Dis. 73:117-122.

14. Pan, Z., Yang, X. B., Pivonia, S., Xue, L., Pasken, R., and Roads, J. 2006. Long-term prediction of soybean rust entry into the continental United States. Plant Dis. 90:840-846.

15. Patil, V. S., Wuike, R. V., Thakare, C. S., and Chirame, B. B. 1997. Viability of uredospores of Phakopsora pachyrhizi syd. at different storage conditions. J. Maharashtra Agric. Univ. 22:260-261.

16. Pfender, W. F., and Vollmer, S. S. 1999. Freezing temperature effect on survival of Puccinia graminis subsp. graminicola in Festuca arundinacea and Lolimu perenne. Plant Dis. 83:1058-1062.

17. Pivonia, S., and Yang, X. B. 2004. Assessment of the potential year-round establishment of soybean rust throughout the world. Plant Dis. 88:523-529.

18. Pivonia, S., and Yang, X. B. 2005. Assessment of epidemics potential of soybean rust in the United States. Plant Dis. 89:678-682.

19. Rossi, R. L. 2003. First report of Phakopsora pachyrhizi, the causal organism of soybean rust in the province of Misiones, Argentina. Plant Dis. 87:102.
20. Schneider, R. W., Hollier, C. A., Whitman, H K., Palm, M. E., McKemy, J. M., Hernandez, J. R., Levy, L., and DeVries-Paterson, R. 2005. First report of soybean rust caused by Phakopsora pachyrhizi in the continental United States. Plant Dis. 89:774.

21. Schein, R. D. 1962. Storage viability of bean rust uredospores. Phytopathology 52:653-657.

22. Tan, Y. 1994. Epidemiology of soybean rust in China. Pages 50-58 in: Advances of Soybean rust Research. Y. Tan, ed. Hubei Science and Technology Publishing House, Wuhan, China.

23. Tschanz, A. T., Wang, T. C., and Tsai, B. Y. 1986. Recent advances in soybean rust research at AVRDC. Pages 237-245 in: Soybeans in Tropical and Subtropical Cropping System. S. Shanmugasundaram and E. W. Sulzberger, eds. AVRDC, Shanhuna, Tainan, Taiwan.

24. Twizeyimana, M., Bandyopadhyay, R., Ojiambo, P. S., Paul, C., and Hartman, G. L. 2006. A detached leaf method to evaluated soybean for resistance to rust. Proceeding of the National Soybean Rust Symposium, St. Louis. Plant Management Network. Online publication.

25. Yang, X. B., Tschanz, A. T., Dowler, W. M., and Wang, T. C. 1991. Development of yield loss models in relation to reductions of components of soybean infected with Phakopsora pachyrhizi. Phytopathology 81:1420-1426.

26. Yorinori, J. T., Paiva, W. M., Frederick, R. D., Costamilan, L. M., Bertagnolli, P. F., Hartman, G. L., Goday, C. V., and Nunes, J., Jr. 2005. Epidemics of soybean rust (Phakopsora pachyrhizi) in Brazil and Paraguay from 2001 to 2003. Plant Dis. 89:675-677. 